\title{
Development of thermoplastic elastomers based on maleated ethylene propylene rubber (m-EPM) and polypropylene (PP) by dynamic vulcanization
}

\author{
K. Chatterjee, K. Naskar* \\ Rubber Technology Centre, Indian Institute of Technology, Kharagpur, Kharagpur-721302, West Bengal, India
}

Received 24 May 2007; accepted in revised form 3 July 2007

\begin{abstract}
Dicumyl peroxide (DCP)-cured thermoplastic vulcanizates (TPVs) based on blends of maleated ethylene propylene rubber (m-EPM) and polypropylene (PP) using maleated-PP as a compatibilizer have been developed. Physical properties of these TPVs change significantly with concentrations of DCP and rubber/plastic blend ratios. Important correlations were obtained from rheometer delta torque values with various physical properties of the TPVs like tension set and crosslink density etc. Wide angle X-ray diffraction study confirms that concentration of DCP has a strong influence on the crystallinity of PP, which might affect the final physical properties of TPVs. The recyclability and ageing characteristics of these TPVs are also found excellent.
\end{abstract}

Keywords: polymer blends and alloys, maleated ethylene propylene rubber, polypropylene, dynamic vulcanization, peroxide

\section{Introduction}

A thermoplastic elastomer (TPE) is defined as a polymeric material with properties and functional performance similar to those of a conventional vulcanized rubber; still it can be processed in a molten state as a thermoplastic polymer. Because of their unique characteristics, TPEs find very useful and attractive applications in a variety of markets, such as automotives, buildings and constructions, wires and cables etc. TPEs are gradually replacing conventional vulcanized rubbers or elastomers in the above-mentioned fields of application. TPEs based on rubber/thermoplastic blends are generally classified into two main categories: first category consists of simple uncross-linked blends and is commonly designated by thermoplastic elastomeric olefins (TEO), in the second category, the rubber phase is dynamically vulcanized in presence of a suitable cross-linking or curing agent, giving rise to a thermoplastic vulcanizate (TPV) or dynamic vulcanizate [1-3]. Various TPVs are reported by many authors [4-15]. Very recently Naskar and coworkers [16-21] pursued extensive research on the effects of various peroxides including multifunctional peroxides as cross-linking agents in TPVs. A TPV is typically characterized by finely dispersed (micron-sized) cross-linked rubber particles, distributed in a continuous thermoplastic matrix. Generally the rubber particle size varies in the range of $0.5-2 \mu \mathrm{m}$. Commercialized TPVs are commonly based on the blends of ethylene propylene diene rubber (EPDM) and polypropylene (PP), and to a lesser extent of combinations of natural rubber, butyl rubber or nitrile rubber with either PP or polyethylene. The literature survey indicates that at present TPVs comprise of the fastest growing thermoplastic elastomer market with a global annual growth rate of about $15 \%$.

*Corresponding author, e-mail: knaskar@rtc.iitkgp.ernet.in

(C) BME-PT and GTE 
The unique characteristic of EPDM or EPM rubber is its excellent ageing characteristics due to saturated main chain backbone. Maleated ethylene propylene rubber ( $\mathrm{m}-\mathrm{EPM})$ is basically a chemically modified EPM rubber. Incorporation of polar maleic group gives some additional features to EPM rubber. For instance, m-EPM has moderate tensile strength and elongation at break; it shows very high heat resistance, weather resistance and resistance to different aggressive chemicals like acid, alkali etc. In addition, it exhibits very good electrical properties, excellent fatigue resistance, good abrasion resistance and also good low temperature properties and good adhesion characteristics, especially with polar substrates. Only a limited research has been carried out so far in the field of polar m-EPM rubber based TPVs. There is hardly any openly published literature available in this field because of commercial sensitivity. Potential areas of applications of m-EPM based TPVs could be in automotive industries (under-the-hood applications) and soft-touch appliances.

Cross-linking of elastomers with peroxides has been known for many years already. Mechanism of peroxide cross-linking of EPDM or EPM is very simple. In general, the cross-linking process of high polymers by organic peroxides can be divided into three successive steps. The first step is the homolytic decomposition of peroxide and generation of free radicals. This step is the rate-determining step of the overall reaction. The second step is the abstraction of hydrogen atom from the polymer chain, resulting in stable peroxide decomposition products and polymer radicals. The third and final step consists of the combination of two polymer radicals to form a $\mathrm{C}-\mathrm{C}$ crosslink. Sometimes, undesired side reactions like disproportionation or chain scission can also occur during the cross-linking process [22-24].

The basic objective of the present paper is to investigate the effects of dicumyl peroxide as cross-linking agent at a fixed and as well as at varied $\mathrm{PP} / \mathrm{m}$-EPM blend ratios in dynamically vulcanized blends using maleated-PP as a compatibilizer. The preparation, characterization and various properties of these new TPVs have been extensively studied.

\section{Experimental}

\subsection{Materials used}

Polypropylene, Koylene ${ }^{\circledR}$ was obtained from Reliance Industries, India having a density of $0.91 \mathrm{~g} / \mathrm{cc}$ and melt flow index (MFI) of $12 \mathrm{~g} / 10 \mathrm{~min}$ measured at $230^{\circ} \mathrm{C}$ and $2.16 \mathrm{~kg}$ load. Maleated PP (m-PP) was obtained from Vin Industries, New Delhi, India. The MFI of the m-PP, measured at $230^{\circ} \mathrm{C}$ and $2.16 \mathrm{~kg}$ load is $60.20 \mathrm{~g} / 10 \mathrm{~min}$. The extent of maleic anhydride (MAH) is $0.9-1.0 \%$. MEPM was obtained from DSM Elastomers, The Netherlands, having $2.1 \mathrm{wt} \%$ of maleic anhydride, $\mathrm{C}_{2} / \mathrm{C}_{3}: 50 / 50$, and a density of $0.86 \mathrm{~g} / \mathrm{cc}$. The number average molecular weight of m-EPM $\left(M_{n}\right)$ is $45000 \mathrm{~g} / \mathrm{mol}$, weight average molecular weight $\left(M_{w}\right)$ is $90000 \mathrm{~g} / \mathrm{mol}$ and $\mathrm{Z}$-average molecular weight $\left(M_{z}\right)$ is $180000 \mathrm{~g} / \mathrm{mol}$ as obtained from gel permeation chromatography (GPC). Dicumyl peroxide (DCP) (98\%) and triallyl cyanurate (TAC) (50\%) were obtained from Akzo Nobel Polymer Chemicals, The Netherlands. DCP was used as the primary cross-linking agent and TAC was used as a co-agent (booster for peroxide).

\subsection{Preparation of TPVs}

All m-EPM based TPVs were prepared by a batch process in a Brabender Plasti-Corder PLE-330, having a mixing chamber volume of $70 \mathrm{~cm}^{3}$. The batch size was kept 60-65 grams. The mixer temperature was kept at $180-190^{\circ} \mathrm{C}$ in order to melt PP. A constant rotor (cam type) speed of $80 \mathrm{rpm}$ was used during mixing.

$\mathrm{PP}$ and $\mathrm{m}$-PP were first melt mixed. Then m-EPM was added together with paraffinic oil (process aid). Finally the cross-linking agents (DCP and TAC) were added. Mixing was continued for another 4 minutes to achieve the dynamic vulcanization. Immediately after mixing, the composition was removed from the mixer chamber and while still molten, passed once through a cold two-roll mill to achieve a sheet of about $2 \mathrm{~mm}$ thickness. The sheet was then cut and pressed for 4 minutes in a compression moulding machine (Moore Press, Birmingham, UK) at $200^{\circ} \mathrm{C}$ and $5 \mathrm{MPa}$ pressure. Aluminum foil was placed between the sheet and the press plates. The sheet was then cooled down to room temperature under pressure. Test specimens were die-cut from the compression molded sheet 
and used for testing after 24 hours of storage at room temperature.

\subsection{Testing procedures}

\subsubsection{Curing characteristics}

Curing characteristics of only m-EPM rubber (without any PP) containing cross-linking agents, DCP/TAC were carried out by using Monsanto Rheometer R100S (an oscillating disc rheometer, ODR) at $180^{\circ} \mathrm{C}$ for 30 minutes.

\subsubsection{Mechanical properties}

Tensile tests were carried out according to ASTM D412-98 on dumb-bell shaped specimens using a universal tensile testing machine Hounsfield H10KS at a constant cross-head speed of $500 \mathrm{~mm} / \mathrm{min}$.

Hardness of the samples was measured by a Durometer (Shore A type) as per ASTM D 2240.

Tension set was measured in universal tensile testing machine Hounsfield H10KS. The test was carried out at room temperature after stretching the TPV samples for 10 minutes at $100 \%$ elongation according to ASTM D 412-98.

\subsubsection{Cross-link density}

The overall cross-link density of the TPV samples was determined on the basis of equilibrium solventswelling measurements (in cyclohexane at 23$25^{\circ} \mathrm{C}$ ) by application of the well-known modified Flory-Rehner equation for tetrafunctional networks. A $2 \mathrm{~mm}$ thick sample was submerged in cyclohexane. After 24 hours, the cyclohexane was refreshed. After another 24 hours, the swollen sample was weighed, dried and weighed again. From the degree of swelling, the crosslink density ( $v$ ) was calculated by modified Flory-Rehner equation (1):

$v=-\frac{1}{V_{s}} \cdot \frac{\ln \left(1-V_{r}\right)+V_{r}+\chi V_{r}^{2}}{V_{r}^{1 / 3}-0.5 \cdot V_{r}}[\mathrm{~mol} / \mathrm{ml}]$

where $V_{s}$ - molar volume of cyclohexane, $\chi$ - polymer-swelling solvent interaction parameter or Flory-Huggins parameter, which in this cases is 0.3 and $V_{r}$ is the volume fraction of rubber in the swollen network, $V_{r}$ is expressed as $V_{r}=1 /\left(A_{\mathrm{r}}+1\right)$ where, $A_{r}$ is the ratio of the volume of absorbed cyclohexane to that of rubber after swelling.

\subsubsection{X-ray diffraction}

Wide angle X-ray diffraction (WAXS) was used to evaluate the influence of peroxide on the PP crystal structure in the blend. WAXS was carried out in Philips PW 1710 diffractometer $\left(\mathrm{CuK}_{\alpha}\right.$ target). The samples were scanned from $2 \theta=10$ to $50^{\circ}$ with a scanning rate of $30^{\circ} / \mathrm{min}$.

\subsubsection{Recycling study}

The compression moulded TPV samples were again melt-mixed in the internal mixer for 4 minutes. Then they were remolded and finally properties after recycling were determined.

\subsubsection{Ageing test}

Ageing test was carried out keeping the TPV samples in an ageing oven at $100^{\circ} \mathrm{C}$ for 72 hours.

\section{Results and discussion}

\subsection{Influence of peroxide at a fixed blend ratio}

\subsubsection{Mechanical properties}

Table 1 shows TPV compositions with different DCP concentrations $(0-3 \mathrm{phr})$ at a fixed blend ratio and Table 2 shows their corresponding mechanical properties. In this case, $10 \mathrm{phr}$ (previously optimized concentration) of m-PP was used as a compatibilizer for $\mathrm{m}$-EPM and PP blends; since $\mathrm{m}$-EPM is polar in nature whereas PP is a non-polar polymer.

From Table 2, it is seen that tensile strength of $\mathrm{m}$ EPM based TPVs varies from 3.5 to $7.3 \mathrm{MPa}$ and elongation at break varies from 120 to $240 \%$. Tensile strength and elongation reach a maximum at $2 \mathrm{phr}$ of DCP concentration. During vulcanization, two competing processes take place simultaneously in presence of DCP. One is cross-linking in rubber

Table 1. TPV compositions (in parts per hundred rubber or phr) with different DCP concentrations at a fixed $\mathrm{m}-\mathrm{EPM} / \mathrm{PP}$ blend ratio

\begin{tabular}{|l|c|c|c|c|c|c|}
\hline Components & N-01 & N-02 & N-03 & N-04 & N-05 & N-06 \\
\hline m-EPM & 100 & 100 & 100 & 100 & 100 & 100 \\
\hline PP & 60 & 60 & 60 & 60 & 60 & 60 \\
\hline m-PP & 10 & 10 & 10 & 10 & 10 & 10 \\
\hline Paraffinic oil & 25 & 25 & 25 & 25 & 25 & 25 \\
\hline DCP (98\%) & 0 & 1.0 & 1.5 & 2.0 & 2.5 & 3.0 \\
\hline TAC (50\%) & 0 & 4 & 4 & 4 & 4 & 4 \\
\hline
\end{tabular}


Table 2. Physical properties of different TPVs

\begin{tabular}{|l|c|c|c|c|c|c|}
\hline \multicolumn{1}{|c|}{ Physical properties } & $\mathbf{N - 0 1}$ & $\mathbf{N - 0 2}$ & $\mathbf{N - 0 3}$ & $\mathbf{N - 0 4}$ & $\mathbf{N - 0 5}$ & $\mathbf{N - 0 6}$ \\
\hline Tensile strength [MPa] & 3.5 & 6.3 & 6.6 & 7.3 & 6.2 & 5.7 \\
\hline Elongation at break [\%] & 120.0 & 178.0 & 219.0 & 240.0 & 159.0 & 177.0 \\
\hline Modulus at 50\% [MPa] & 3.5 & 3.9 & 4.0 & 4.1 & 4.2 & 4.3 \\
\hline Modulus at 100\% [MPa] & 4.5 & 5.0 & 5.1 & 5.2 & 5.8 & 5.9 \\
\hline Modulus at 150\% [MPa] & - & 5.7 & 5.8 & 5.9 & 6.1 & 6.3 \\
\hline Hardness [Shore A] & 60.0 & 65.0 & 68.0 & 70.0 & 72.0 & 73.0 \\
\hline Overall crosslink density v-105 [mol/ml] & - & 14.5 & 15.3 & 19.6 & 20.7 & 22.1 \\
\hline Tension set [\%] & - & 16.1 & 14.2 & 12.2 & 10.2 & 8.2 \\
\hline Tear strength [N/mm] & - & 20.1 & 35.0 & 42.4 & 45.8 & 52.1 \\
\hline
\end{tabular}



Figure 1. General scheme of $\beta$-chain scission of PP in presence of peroxide

phase and the other is degradation in PP-phase by $\beta$-chain scission by abstraction of tertiary hydrogen atoms from the main chain of the olefinic polymer $[23,24]$. General scheme of $\beta$-chain scission of PP in presence of peroxide is shown in Figure 1.

In this particular case, 2 phr concentration of DCP is found to be optimum. Other mechanical properties like the moduli, hardness, tear strength and overall cross-link density of TPVs have also been found to increase with increasing DCP concentration. Modulus at $50 \%$ varies from 3.5 to $4.3 \mathrm{MPa}$, modulus at $100 \%$ varies from 5 to $5.9 \mathrm{MPa}$ and modulus at $150 \%$ varies from 5.7 to $6.3 \mathrm{MPa}$ with increasing DCP concentration from 1 to $3 \mathrm{phr}$. Hardness is lying in between 60 to 73 Shore A. Tear strength increases from 20 to $52 \mathrm{~N} / \mathrm{mm}$. On the other hand, the tension set value decreases from 16.1 to $8.2 \%$ indicating better elastic recovery behaviour of these TPVs.

\subsubsection{Curing characteristics}

In order to achieve a better in-sight into the chemistry involved with dynamic vulcanization in $\mathrm{m}$ $\mathrm{EPM} / \mathrm{PP}$ blends in presence of DCP, it is essential to know the vulcanization characteristics of pure $\mathrm{m}$-EPM gum compounds without any PP at various DCP concentrations. Table 3 shows the recipes of m-EPM gum compounds at different DCP concentrations for ODR study.
Table 3. Recipes of m-EPM gum compounds at different DCP concentrations

\begin{tabular}{|l|c|c|c|c|c|}
\hline \multicolumn{1}{|c|}{ Ingredients } & $\mathbf{N - 0 7}$ & $\mathbf{N - 0 8}$ & $\mathbf{N - 0 9}$ & $\mathbf{N - 1 0}$ & $\mathbf{N - 1 1}$ \\
\hline m-EPM & 100 & 100 & 100 & 100 & 100 \\
\hline Paraffinic oil & 25 & 25 & 25 & 25 & 25 \\
\hline DCP (98\%) & 1.0 & 1.5 & 2.0 & 2.5 & 3.0 \\
\hline TAC (50\%) & 4 & 4 & 4 & 4 & 4 \\
\hline
\end{tabular}

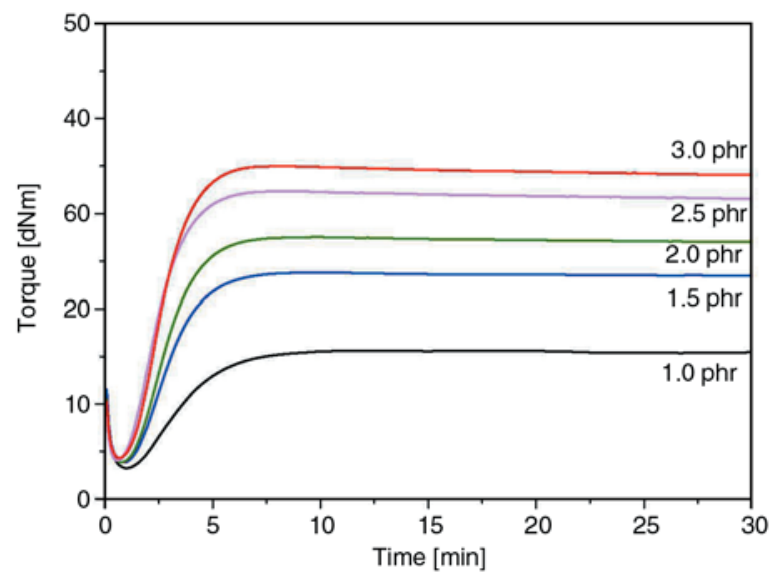

Figure 2. Rheograms of pure m-EPM vulcanizates containing various DCP concentrations at $180^{\circ} \mathrm{C}$

Figure 2 shows rheograms of pure m-EPM vulcanizates at $180^{\circ} \mathrm{C}$ and Table 4 demonstrates the corresponding rheometer data.

The delta torque (maximum-minimum torque) values obtained from ODR generally correlates with the cross-linking efficiency of the peroxide, which is defined as the number of moles of chemical cross-links formed per mole of peroxide. It should 
Table 4. Rheometer data of $\mathrm{m}$-EPM gum compounds at $180^{\circ} \mathrm{C}$ for 30 minutes

\begin{tabular}{|c|c|c|c|c|c|}
\hline Formulation & Minimum torque [dNm] & Maximum torque [dNm] & Delta torque [dNm] & $\mathbf{T}_{\mathbf{C 9 0}}[\mathbf{m i n}]$ & $\mathbf{T}_{\mathbf{S 2}}$ [min] \\
\hline N-07 & 3.23 & 15.62 & 12.39 & 6.3 & 2.1 \\
\hline N-08 & 3.82 & 23.76 & 19.94 & 5.0 & 1.6 \\
\hline N-09 & 3.85 & 27.50 & 23.65 & 4.8 & 1.5 \\
\hline N-10 & 4.04 & 32.34 & 28.30 & 4.3 & 1.2 \\
\hline N-11 & 4.29 & 35.00 & 30.71 & 4.5 & 1.3 \\
\hline
\end{tabular}

be noted however, that the latter could be measured by static vulcanization only in absence of PP; which is not exactly a one-to-one comparison to dynamic vulcanization, due to lack of high shear rate and the longer time scales.

From Table 4, it is observed that delta torque values increase with increasing peroxide concentrations. It clearly indicates that with increasing DCP

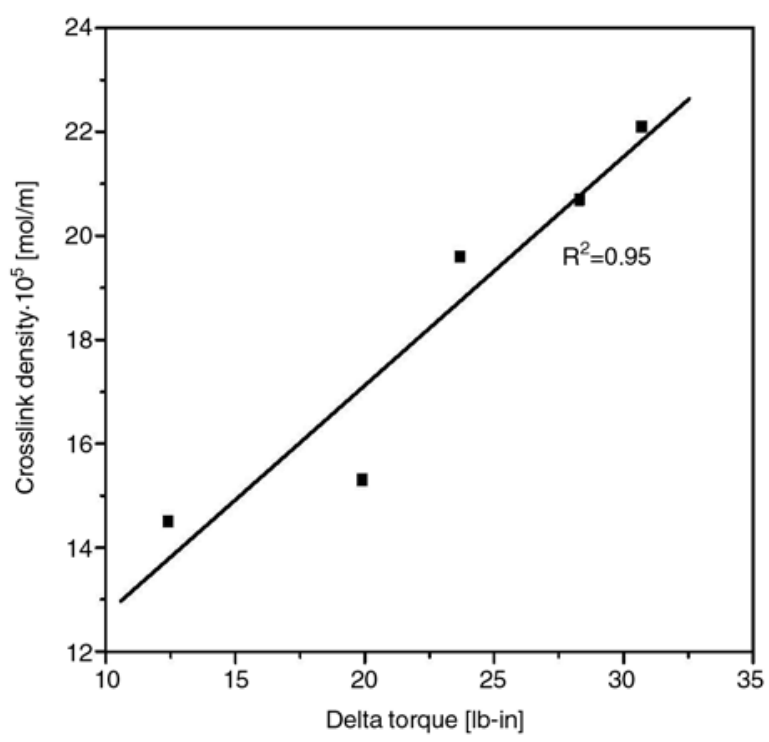

Figure 3. Cross-link density as a function of delta torque

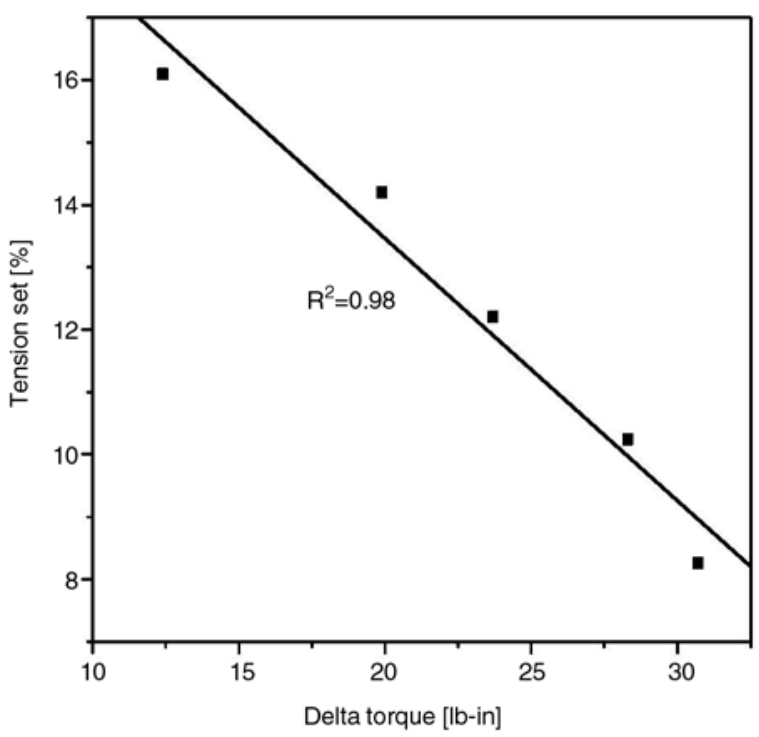

Figure 4. Tension set as a function of delta torque concentration more cumyloxy or methyl radicals are formed, which basically leads to higher extent of cross-linking in m-EPM phase. Reduction in optimum cure time $\left(T_{c 90}\right)$ and scorch time $\left(T_{S 2}\right)$ with increasing DCP concentrations also explain the same. An attempt was made to find whether there is any correlation between ODR delta torque and various physical properties of TPVs. Figures 3 and 4 show relations between ODR delta torque and cross-link density and tension set of TPVs respectively. Linear correlations have been noticed which indicate that ODR delta torque of DCP/ TAC-cured mEPM (without any PP though) is directly proportional to the cross-link density and tension set values of TPVs.

In order to understand the deterioration of physical properties of TPVs at higher concentration of DCP, wide angle X-ray diffraction (WAXS) study has been carried out to check if there is any influence of DCP on PP crystallinity. Figure 5 shows WAXS graph of TPVs with $1 \mathrm{phr}$ of DCP. The major peaks correspond to 130,111, 131 and 041 planes in the crystal respectively. The pattern of PP in the blend samples shows $\alpha$ form (monoclinic) only, because there is no line at $2 \theta=16.10$, which is normally associated with $\beta$ form (hexagonal). All other XRD graphs of TPV samples containing various DCP concentrations are not shown, because the basic

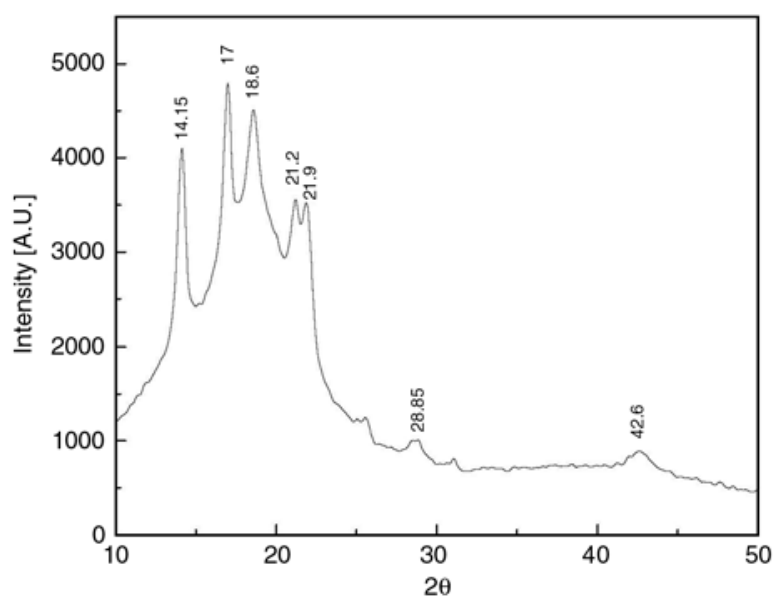

Figure 5. XRD graphs of TPV with $1.0 \mathrm{phr}$ of DCP 
Table 5. Percent crystallinity of different TPVs with different DCP concentrations

\begin{tabular}{|c|c|}
\hline $\begin{array}{c}\text { Sample designation and } \\
\text { peroxide concentration }\end{array}$ & \% crystallinity \\
\hline $\mathrm{N}-01(0 \mathrm{phr})$ & 56 \\
\hline $\mathrm{N}-02(1 \mathrm{phr})$ & 48 \\
\hline $\mathrm{N}-04(2 \mathrm{phr})$ & 42 \\
\hline $\mathrm{N}-06(3 \mathrm{phr})$ & 40 \\
\hline
\end{tabular}

nature of all other graphs are very similar. From the XRD graphs, percent crystallinity was calculated for different samples, which is shown in Table 5.

Table 5 shows that the $\%$ crystallinity decreases with increasing concentration of peroxide. From the table it is also observed that, without DCP the crystallinity is maximum, which is $56 \%$. With the increase in concentration of DCP from 1 to $3 \mathrm{phr}$, the ctystallinity decreases from 48 to $40 \%$. This explains why the mechanical properties of TPVs decrease at higher DCP concentration.

\subsubsection{Recycling study}

One of the major advantages of the TPEs and TPV is its ability of recycling without significant deterioration of mechanical properties. Recycling study has been performed on the TPVs with varied concentrations of DCP. After the recycling, it is found that there are only minor changes in the properties, which indicates that theses TPVs show very good recyclability. Table 6 shows the properties after the recycling.

\subsubsection{Ageing study}

Table 7 shows the physical properties of the aged samples. The results show that there are not significant changes after ageing. So the ageing characteristics are good for these TPVs. Reason for achieving good ageing characteristics is that upon peroxide cross-linking $\mathrm{C}-\mathrm{C}$ bond is formed, which has high bond energy.

\subsection{Influence of peroxide at varied blend ratios}

\subsubsection{Mechanical properties}

Table 8 shows the TPV compositions at varied $\mathrm{m}$ EPM/PP ratios at a fixed DCP concentration of $2 \mathrm{phr}$ and Table 9 shows their corresponding properties.

From Table 9, it is noticed that the tensile strength varies from 4.5 to $8.8 \mathrm{MPa}$ as the amount of $\mathrm{PP}$ increases from 20 to $100 \mathrm{phr}$. However the elongation at break decreases from 210 to $150 \%$. This is because of the fact that PP itself has high strength but low elongation at break. The modulus at 50\% increases from 1.9 to $7.4 \mathrm{MPa}$; the modulus at $100 \%$ increases from 2.7 to $8.3 \mathrm{MPa}$ and the modu-

Table 8. TPV compositions (in phr) at varied m-EPM/PP ratios at a fixed DCP concentration

\begin{tabular}{|l|c|c|c|c|c|}
\hline \multicolumn{1}{|c|}{ Ingredients } & $\mathbf{N - 1 2}$ & $\mathbf{N - 1 3}$ & $\mathbf{N - 0 4}$ & $\mathbf{N - 1 4}$ & $\mathbf{N - 1 5}$ \\
\hline m-EPM & 100 & 100 & 100 & 100 & 100 \\
\hline PP & 20 & 40 & 60 & 80 & 100 \\
\hline m-PP & 10 & 10 & 10 & 10 & 10 \\
\hline Paraffinic oil & 25 & 25 & 25 & 25 & 25 \\
\hline DCP (98\%) & 2 & 2 & 2 & 2 & 2 \\
\hline TAC (50\%) & 4 & 4 & 4 & 4 & 4 \\
\hline
\end{tabular}

Table 6. Physical properties of TPVs with different DCP concentrations after recycling

\begin{tabular}{|l|c|c|c|c|c|c|}
\hline \multicolumn{1}{|c|}{ Properties } & $\mathbf{N - 0 1}$ & $\mathbf{N - 0 2}$ & $\mathbf{N - 0 3}$ & $\mathbf{N - 0 4}$ & $\mathbf{N - 0 5}$ & N-06 \\
\hline Tensile strength $[\mathrm{MPa}]$ & 3.4 & 5.0 & 5.2 & 5.7 & 5.5 & 5.4 \\
\hline Elongation at break $[\%]$ & 110 & 140 & 149 & 190 & 156 & 140 \\
\hline Modulus at 50\% $[\mathrm{MPa}]$ & 3.2 & 3.5 & 3.9 & 4.0 & 4.3 & 4.9 \\
\hline Modulus at 100\% $[\mathrm{MPa}]$ & 3.4 & 4.9 & 5.1 & 5.2 & 5.8 & 6.0 \\
\hline Tear strength $[\mathrm{N} / \mathrm{mm}]$ & 18 & 25 & 30.2 & 35.1 & 40.1 & 45.2 \\
\hline
\end{tabular}

Table 7. Physical properties of TPVs before and after ageing

\begin{tabular}{|c|c|c|c|c|}
\hline Sample designation & $\begin{array}{c}\text { Tensile strength } \\
\text { (before ageing) }\end{array}$ & $\begin{array}{c}\text { Tensile strength } \\
\text { (after ageing) }\end{array}$ & $\begin{array}{c}\text { Elongation at break } \\
\text { (before ageing) }\end{array}$ & $\begin{array}{c}\text { Elongation at break } \\
\text { (after ageing) }\end{array}$ \\
\hline N-02 & 6.3 & 6.2 & 178 & 150 \\
\hline N-03 & 6.6 & 6.3 & 219 & 195 \\
\hline N-04 & 7.3 & 7.1 & 240 & 210 \\
\hline N-05 & 6.2 & 5.9 & 159 & 148 \\
\hline N-06 & 5.7 & 5.5 & 177 & 139 \\
\hline
\end{tabular}


Table 9. Physical properties of different blends

\begin{tabular}{|l|c|c|c|c|c|}
\hline \multicolumn{1}{|c|}{ Properties } & $\mathbf{N - 1 2}$ & $\mathbf{N - 1 3}$ & $\mathbf{N - 0 4}$ & $\mathbf{N - 1 4}$ & $\mathbf{N - 1 5}$ \\
\hline Tensile strength [MPa] & 4.5 & 6.5 & 7.3 & 8.2 & 8.8 \\
\hline Elongation at break [\%] & 210.0 & 215.0 & 240.0 & 191.0 & 150.0 \\
\hline Modulus at 50\% [MPa] & 1.9 & 3.3 & 4.1 & 5.8 & 7.4 \\
\hline Modulus at 100\% [MPa] & 2.7 & 4.4 & 5.2 & 6.8 & 8.3 \\
\hline Modulus at 150\% [MPa] & 3.5 & 5.4 & 5.9 & 7.7 & 8.8 \\
\hline Tear strength [N/mm] & 23.8 & 40.6 & 42.4 & 54.1 & 66.2 \\
\hline Hardness [Shore A] & 60.0 & 68.0 & 70.0 & 76.0 & 81.0 \\
\hline Tension set [\%] & 8.3 & 10.2 & 12.2 & 14.2 & 18.1 \\
\hline
\end{tabular}

lus at $150 \%$ increases from 3.5 to $8.8 \mathrm{MPa}$. Tear strength is also increased from 23.8 to $66.2 \mathrm{~N} / \mathrm{mm}$ with increasing amount of PP. Hardness varies from 60 to 81 Shore A. Tension set is found to increase indicating poor set property. The reason for increased tensile strength, modulus and hardness with the increasing amount of PP is due to the increased thermoplastic hard component in the blends.

\section{Conclusions}

Peroxide-cured TPVs based on blends of m-EPM and PP using $\mathrm{m}-\mathrm{PP}$ as a compatibilizer have been developed. Physical properties of these TPVs change significantly with DCP concentrations and rubber/plastic blend ratios. The concentration of DCP is optimized at 2 phr. Important correlations were obtained from ODR delta torque values with various physical properties of m-EPM based TPVs like tension set and crosslink density. WAXS data indicate that concentration of DCP has a strong influence on the crystallinity of PP that might affect the final physical properties of TPVs. The recyclability and ageing properties of the TPVs are found excellent.

\section{References}

[1] Legge N. R., Holden G., Schroeders H. E.: Thermoplastic elastomer: A Comprehensive review. Hanser, Munich (1987).

[2] Bhowmick A. K., Stephens H. L.: Handbook of Elastomers: New developments and technology. Marcel Dekker, New York (1988).

[3] De S. K., Bhowmick A. K.: Thermoplastic elastomers from rubber plastic blends. Horwood, London (1990).

[4] Fisher W. K.: Thermoplastic blend of partially cured monoolefin copolymer rubber and polyolefin plastic. US Patent 3862106, USA (1973).
[5] Coran A. Y., Patel R.: Rubber-thermoplastic compositions. Part IV. Thermoplastic vulcanizates from various rubber-plastic combinations. Rubber Chemistry and Technology, 54, 892-903 (1981).

[6] Coran A. Y., Das B., Patel R. P.: Thermoplastic vulcanizates of olefin rubber and polyolefin resin. US Patent 4130535, USA (1978).

[7] Abdou-Sabet S., Fath M. A.: Thermoplastic elastomeric blends of olefin rubber and polyolefin resin. US Patent 4311628, USA (1982).

[8] Coran A. Y., Patel R.: Rubber-thermoplastic compositions. Part I. EPDM-polypropylene thermoplastic vulcanizates. Rubber Chemistry and Technology, 53, 141-150 (1980).

[9] Coran A. Y., Patel R.: Rubber-thermoplastic compositions. Part II. NBR-nylon thermoplastic elastomeric compositions. Rubber Chemistry and Technology, 53, 781-794 (1980).

[10] Coran A. Y., Patel R.: Rubber-thermoplastic compositions. Part III. Predicting elastic moduli of melt mixed rubber-plastic blends. Rubber Chemistry and Technology, 54, 91-100 (1981).

[11] Coran A. Y., Patel R., Williams D.: Rubber-thermoplastic compositions. Part V. Selecting polymers for thermoplastic vulcanizates. Rubber Chemistry and Technology, 55, 116-136 (1982).

[12] Coran A. Y., Patel R.: Rubber-thermoplastic compositions. Part VI. The swelling of vulcanized rubber-plastic compositions in fluids. Rubber Chemistry and Technology, 55, 1063-1077 (1981).

[13] Coran A. Y., Patel R.: Rubber-thermoplastic compositions. Part VII. Chlorinated polyethylene rubber nylon compositions. Rubber Chemistry and Technology, 56, 210-225 (1983).

[14] Coran A. Y., Patel R.: Rubber-thermoplastic compositions. Part VIII. Nitrile rubber polyolefin blends with technological compatibilization. Rubber Chemistry and Technology, 56, 1045-1060 (1983).

[15] Coran A. Y.: Vulcanization: conventional and dynamic. Rubber Chemistry and Technology, 68, 351-375 (1995).

[16] Naskar K., Noordermeer J. W. M.: Dynamically vulcanized PP/EPDM blends-Effects of different types of peroxide on the properties. Rubber Chemistry and Technology, 76, 1001-1018 (2003). 
[17] Naskar K., Noordermeer J. W. M.: Multifunctional peroxide as a means to improve properties of dynamically vulcanized PP/EPDM blends. Kautschuk, Gummi, Kunststoffe, 57, 235-239 (2004).

[18] Naskar K., Kokot D., Noordermeer J. W. M.: Influence on various stabilizers on aging of dicumyl peroxide cured polypropylene/ethylene-propylene-diene thermoplastic vulcanizates. Polymer Degradation and Stability, 85, 831-839 (2004).

[19] Naskar K., Noordermeer J. W. M.: Dynamically vulcanized PP/EPDM blends - effects of multifunctional peroxides as a crosslinking agents. Rubber Chemistry and Technology. 77, 955-971 (2004).

[20] Naskar K., Noordermeer J. W. M.: Thermoplastic elastomers by dynamically vulcanization. Progress in Rubber, Plastics and Recycling Technology, 21, 1-26 (2005).
[21] Datta S., Naskar K., Jelenic J., Noordermeer J. W. M.: Dynamically vulcanized PP/EPDM blends by multifunctional peroxides: Characterization with various analytical techniques. Journal of Applied Polymer Science, 98, 1393-1403 (2005).

[22] Loan L. D.: Mechanism of peroxide vulcanization of elastomers. Rubber Chemistry and Technology, 40, 149-176 (1967).

[23] Baldwin F. P., Borzel P., Cohen C. A., Makowski H. S., Van de Castle J. F.: The influence of residual olefin structure on EPDM vulcanization. Rubber Chemistry and Technology, 43, 522-548 (1970).

[24] Hofmann W., Crosslinking agents in ethylene-propylene rubbers. Kautschuk, Gummi, Kunststoffe, 40, 308-332 (1987). 